\title{
Treated wastewater irrigation effects on soil hydraulic conductivity and aggregate stability of loamy soils in Israel
}

\author{
Karsten Schacht ${ }^{1,2^{*}}$, Bernd Marschner ${ }^{1}$ \\ ${ }^{1}$ Institute of Geography, Department of Soil Science and Soil Ecology, Ruhr-University Bochum, Universitätsstrasse 150, 44801 Bochum, \\ Germany. \\ ${ }^{2} \mathrm{CIH}^{\mathrm{LMU}}$ Center for International Health, Department of Infectious Diseases and Tropical Medicine at the University of Munich, \\ Lepoldstrasse 7, 80802 Munich, Germany. \\ ${ }^{*}$ Corresponding author. E-mail: karsten.schacht@rub.de
}

\begin{abstract}
The use of treated wastewater (TWW) for agricultural irrigation becomes increasingly important in water stressed regions like the Middle East for substituting fresh water (FW) resources. Due to elevated salt concentrations and organic compounds in TWW this practice has potential adverse effects on soil quality, such as the reduction of hydraulic conductivity (HC) and soil aggregate stability (SAS). To assess the impact of TWW irrigation in comparison to FW irrigation on $\mathrm{HC}$, in-situ infiltration measurements using mini disk infiltrometer were deployed in four different long-term experimental orchard test sites in Israel. Topsoil samples $(0-10 \mathrm{~cm})$ were collected for analyzing SAS and determination of selected soil chemical and physical characteristics.

The mean $\mathrm{HC}$ values decreased at all TWW sites by $42.9 \%$ up to $50.8 \%$ compared to FW sites. The SAS was $11.3 \%$ to $32.4 \%$ lower at all TWW sites. Soil electrical conductivity (EC) and exchangeable sodium percentage (ESP) were generally higher at TWW sites. These results indicate the use of TWW for irrigation is a viable, but potentially deleterious option, as it influences soil physical and chemical properties.
\end{abstract}

Keywords: Hydraulic conductivity; Soil aggregate stability; Irrigation; Treated wastewater; Israel.

\section{INTRODUCTION}

The eastern Mediterranean countries face increasing water stress due to enhanced water withdrawal as well as higher annual mean temperatures and decreased annual precipitation from climate change (Milano et al., 2012; Smiatek et al., 2011). In this region, supplementary agricultural irrigation is necessary due to the insufficient precipitation. As treated wastewater (TWW) can be considered a reliable water source for agricultural irrigation due to its continuous availability throughout the year, its importance is going to increase with decreasing freshwater (FW) availability (Friedler, 2001). The use of TWW for agricultural irrigation in water stressed regions alleviates the pressure on available natural water resources and releases FW resources to be available for other purposes, improving water security.

Israel is a world leader in TWW reuse for agricultural irrigation (Hamilton et al., 2007). According to the Israeli Water Authority (2014), 35.4\% of Israel's total FW consumption $\left(1212.7 \mathrm{hm}^{3}\right)$ in 2012 was used for agricultural purposes and $57.2 \%$ for domestic purposes. In 2012, 39.6\% of the water used for agricultural purposes was TWW, a proportion similar to the agricultural FW consumption. Other irrigation water sources were saline (15.7\%) and flood (5.2\%) water (Israeli Water Authority, 2014). Israel's national policy aims for even higher rates of TWW use and further gradual replacement of FW, with improved standards and regulations for TWW reuse in irrigation to be enforced (Inbar, 2007; Provizor, 2009). By the year 2020, almost all municipal wastewater is expected to be treated and reused, mostly for irrigation in the agricultural sector (Brenner, 2012).

TWW quality depends on the originating water source, "pick-up" during usage, treatment grade and technology and post-treatment dilution. Compared to FW, TWW carries a higher proportion of nutrients (e.g. N, P, K) and soluble salts (con- taining e.g. $\mathrm{Cl}, \mathrm{Na}, \mathrm{Ca}, \mathrm{Mg}$ ), organic substances as well as inorganic and organic pollutants (Feigin et al., 1991). Thus, various environmental side effects were found to be associated with TWW irrigation, such as enhanced levels of soil salinity, sodicity and nitrate leaching to the groundwater (Bond, 1998). In Israel, total salt concentrations in TWW were up to twice as high as those found in FW, associated with an increase in the sodium adsorption ratio (SAR) from 2.5 in FW to $5-8$ in the TWW (Feigin et al., 1991). Although the general quality of the TWW improved within the last two decades (Lahav et al., 2010; Levy, 2011), total salt concentration and SAR remained mostly unchanged because these properties are not affected by standard treatment methods. Even so, elevated sodicity and additional higher levels of suspended solids and dissolved organic matter (DOM) are associated with additional detrimental effects on soil physical properties like soil structure, soil aggregate stability (SAS), soil water repellency (SWR) (Schacht et al., 2014; Tarchitzky et al., 2007), and consequently, hydraulic conductivity (HC) (Halliwell et al., 2001; Tarchitzky et al., 1999), as well as yield (Maher et al., 2004). This might change in the future due to the increased proportion of provided desalinated $\mathrm{FW}$ and the implementation of improved tertiary treatment technologies like reverse osmosis (Brenner, 2012; Lahav et al., 2010; Shannon et al., 2008). The effects of TWW irrigation on soil chemical and hydraulic properties in arid and semiarid zones are widely discussed and reviewed by Lado and Ben-Hur (2010). The experiences with long-term TWW irrigation and its effects on soil structure stability in Israel were reviewed by Levy (2011).

Le Bissonnais and Arrouays (1996) identified four main mechanisms responsible for aggregate breakdown with water involvement: a) slaking (in consequence to internal pressure by air entrapment during wetting), b) swelling (due to internal pressure by differential swelling of clay), c) splash (breakdown due to external pressure by raindrop impact) and d) physicochemical dispersion (due to internal attractive forces between 
colloidal particles). Micro irrigation, as practiced in Israel, mainly affects mechanisms a, b and d. While clay swelling is not greatly affected by low exchangeable sodium percentage (ESP) values, clay dispersion is very sensitive to low levels of sodicity (Shainberg and Letey, 1984) and by that to the susceptibility of aggregates to slaking (Levy et al., 2003). Using distilled water for SAS estimation simulates the conditions occurring mainly during the winter, when the soil is leached with electrolyte free rainwater.

Previous studies showed that irrigation with poorly treated TWW is lowering HC. This was explained by biological and physical pore clogging (Magesan et al., 1999; Magesan et al., 2000; Vinten et al., 1983; Viviani and Iovino, 2004) or by high ESP induced soil swelling and dispersion effects (Gharaibeh et al., 2007). In laboratory soil column studies, Levy et al. (1999) applied 5 different TWW qualities to 3 different Israeli soils, finding that the poorest TWW quality reduced HC most. Subsequent leaching with distilled water decreased the $\mathrm{HC}$ further, again the most where the poorest water quality has been applied. Comparing the stability ratios of soils from FW and TWW irrigated sites, Levy and Mamedov (2002) found significantly lower ratios for clayey soils (clay content $>38 \%$ ) irrigated with TWW. However, soils from two other sites with lower clay content ( 8 and $22.5 \%$ ) showed similar stability ratios for all treatments. Bhardwaj et al. (2007) measured the saturated HC of intact and disturbed clayey soil samples and the SAS from an orchard, comparing different irrigation water qualities (FW and TWW) and irrigation systems (mirosprinkler, drip irrigation, rain fed). When considering the TWW and FW at irrigated sites with equivalent irrigation systems, the TWW irrigated soils showed a reduced steady state $\mathrm{HC}$, but no clear trend was observed for the impact on SAS

Nevertheless, the saturated $\mathrm{HC}$ of soils is mostly determined in laboratory and soil column studies using disturbed or undisturbed soil samples. It is suggested that this approach might not reflect the actual processes in the field, as the samples need to be detached from the profile and thereby might have lost their original structure. Moreover, laboratory settings most often do not realistically represent the field processes (Shainberg and Letey, 1984), either by different time or experimental design. Halliwell et al. (2001) state that laboratory studies of clay water systems are easy to predict, but these systems rarely behave ideally under field condition. As opposed to laboratory studies, field experiments for estimating soil hydraulic properties lack the same convenient controllability of conditions, but might be favored because of their better reflection of field scale processes. However, studies comparing field measured hydraulic property results from long time continuously operated test sites using different water qualities are scarce.

The objectives of this study were to determine the impact of different irrigation water quality (i) on SAS and (ii) on HC onsite and under field conditions. For this purpose, long time agricultural test sites were accessed to measure $\mathrm{HC}$ in the field and to take soil samples for subsequent SAS analysis.

\section{MATERIAL AND METHODS Description of test sites}

All four test sites were situated in long-term agricultural experimental orchards in northern Israel, providing replicated plots irrigated with either FW or secondary or tertiary TWW. All orchards were equipped with drip irrigation systems. The field experiments were deployed in May and June 2010. Soil types are described based on the Israeli soil classification (Dan et al., 1972) and translated into the FAO/WRB classification according to Krasnikov and Arnold (2009).

The test site Akko (AK) is located east of Akko city in an avocado plantation $\left(32^{\circ} 55^{\prime} 51^{\prime \prime} \mathrm{N}, 35^{\circ} 06^{\prime} 19^{\prime \prime} \mathrm{E}\right)$. The trees were planted in 1993 with intervals between trees and rows of 6 and $5 \mathrm{~m}$, respectively. Trees were set in parallel rows on mounds and were watered by drip irrigation with TWW or FW at $2 \mathrm{~mm} \mathrm{~d}^{-1}$ in spring and up to $4 \mathrm{~mm} \mathrm{~d}^{-1}$ in summer. The total annual irrigation amount is about $750 \mathrm{~mm}$. Starting 1995, the experimental field was partly irrigated with TWW. The litter was regularly removed. The clayey soil was classified as an alluvial brown Grumusol (WRB: Vertisol). The measuring spots were dried using either special cramps to seal the drip holes or by moving the irrigation tube from the test spot. The topsoil at the spots was set to dry for six days before the measurements were taken.

The test site Ginosar (GI) is a banana plantation established in 2000 on a former date plantation $\left(32^{\circ} 51^{\prime} 24^{\prime \prime} \mathrm{N}, 35^{\circ} 31^{\prime} 15^{\prime \prime}\right.$ E) to study the effect of TWW and FW irrigation on plant growth and health. The banana plants were irrigated using mini drip irrigation tubes. Water analysis data is available on a yearly (FW) or monthly (TWW) basis for the initial experimental period 2001-2004. The annual applied amount of irrigation water was 2000 to $2200 \mathrm{~mm}$. After closure of the initial experiment in 2004, farming within the plantation continued in the same irrigation pattern. The soil was classified as an alluvial brown Grumusol (WRB: Vertisol). The topsoil texture was silty clay. Before performing the infiltration tests, the litter was carefully removed by hand and with a hand broom. The observation spots were chosen beneath the existing drippers. The HC measurements were conducted right before an impending clearing of the plantation. As a preparation of the clearing, any irrigation of the abandoned plantation was ceased. According to the plantation manager, the entire irrigation of the plantation was discontinued about four weeks prior to the execution of the HC measurements.

The test site in the pear plantation close to Rosh Pina (RP) was established in 2004 to evaluate the effects of the change in irrigation water on soil properties and trees due to the construction of a new wastewater treatment plant close to the plantation. Except for the FW section of the test site, the whole plantation was henceforth irrigated with TWW. The pear trees in this plot were about 40 years old and are planted on mounds $\left(32^{\circ} 57^{\prime} 42^{\prime \prime} \mathrm{N}, 35^{\circ} 33^{\prime} 47^{\prime \prime} \mathrm{E}\right)$. Litter was removed regularly. During the dry season, the trees were irrigated 2-3 times a day with a rate of 7-9 $\mathrm{mm} \mathrm{d}^{-1}$, with an annual irrigation volume of approximately $750 \mathrm{~mm}$. The clayey soil was classified as an alluvial brown Grumusol (WRB: Vertisol). The soil at the test spots was allowed to dry for $6 \mathrm{~d}$ before infiltration tests were performed.

The test site Yonatan (YO) is a mango plantation located about $4 \mathrm{~km}$ north-east of the Sea of Galilee $\left(32^{\circ} 53^{\prime} 55^{\prime \prime} \mathrm{N}\right.$, $\left.35^{\circ} 39^{\prime} 51^{\prime \prime} \mathrm{E}\right)$. The experiment, comparing the effect of FW and TWW irrigation on tree growth and quality, was established in 1998. The clayey soil was classified as Basaltic Protogrumusol (WRB: Vertic Leptosol) with a shallow soil development of 0.6 to $0.8 \mathrm{~m}$. The topsoil was allowed to dry for 7 days after moving irrigation tubes from the test spots.

Irrigation water properties provided by the operators of the orchards are given in Table 1. The TWW showed higher electrical conductivity (EC) at all test sites, and higher $\mathrm{pH}$ compared to FW for the test sites AK, RP and YO. Except for the test site GI, where the SAR was higher in FW, TWW generally showed higher EC, higher SAR and higher $\mathrm{pH}$ compared to FW.

Except for GI, all test sites were also subject to SWR measurements reported in Schacht et al. (2014). 
Treated wastewater irrigation effects on soil hydraulic conductivity and aggregate stability of loamy soils in Israel

Table 1. Properties of the different irrigation waters at the four test sites as provided by the respective plantation management (FW freshwater; TWW treated waste water; EC electrical conductivity; SAR sodium adsorption ratio; TSS total suspended solids). Values are given either for the date of measurement or indicate the mean from the given sampling period.

\begin{tabular}{|c|c|c|c|c|c|c|c|c|}
\hline \multirow{2}{*}{$\begin{array}{l}\text { Test site } \\
\text { Crop } \\
\text { Treatment }\end{array}$} & \multicolumn{2}{|c|}{$\begin{array}{c}\text { AK } \\
\text { Avocado }\end{array}$} & \multicolumn{2}{|c|}{$\begin{array}{c}\text { GI } \\
\text { Banana }\end{array}$} & \multicolumn{2}{|c|}{$\begin{array}{c}\text { RP } \\
\text { Pear }\end{array}$} & \multicolumn{2}{|c|}{$\begin{array}{c}\text { YO } \\
\text { Mango }\end{array}$} \\
\hline & FW & TWW & FW & TWW & FW & TWW & FW & TWW \\
\hline Sampling date & \multicolumn{2}{|c|}{17.05 .2010} & \multicolumn{2}{|c|}{$2001-2004$} & 2010 & $2006-2010$ & \multicolumn{2}{|c|}{2010} \\
\hline $\mathrm{EC}(\mathrm{mS} / \mathrm{cm})$ & 0.98 & 1.59 & 1.1 & 1.41 & 0.61 & 1.31 & 0.49 & 0.88 \\
\hline SAR & 0.74 & 3.23 & 3.08 & 2.52 & 0.62 & 4.31 & 0.90 & 3.29 \\
\hline pH & 6.9 & 8.2 & 8.1 & 8.1 & 7.2 & 7.9 & 6.5 & 8.4 \\
\hline TSS (mg/L) & - & 5 & - & 65 & - & 28.9 & - & 25.0 \\
\hline $\mathrm{Na}(\mathrm{mEq} / \mathrm{L})$ & 1.7 & 7.9 & 5.3 & 5.1 & 1.1 & 7.2 & 1.4 & 4.9 \\
\hline $\mathrm{Cl}(\mathrm{mg} / \mathrm{L})$ & 93 & 235 & 7.0 & 4.4 & 38.3 & 167.8 & 38.0 & 99.2 \\
\hline $\mathrm{Ca}+\mathrm{Mg}(\mathrm{mEq} / \mathrm{L})$ & 11.1 & 9.7 & 5.8 & 7.9 & 5.9 & 5.9 & 5.0 & 4.4 \\
\hline
\end{tabular}

\section{Measurement of soil hydraulic conductivity}

The unsaturated hydraulic conductivity was measured using a mini disk infiltrometer (MDI, Decagon Devices Inc., Pullman, WA, USA). It consists of two chambers (water reservoir and bubble chamber), which are connected via a Mariotte tube to provide a constant water pressure head of -0.5 to $-7 \mathrm{~cm}$ (equivalent to -0.05 to $-0.7 \mathrm{kPa}$ ). The bottom of the MDI contains a porous sintered steel disc. The water filled tube is placed on the soil surface resulting in water infiltrating into the soil, with the volume of water and speed of infiltration depending on the sorptivity and hydraulic conductivity of the soil. A pressure head of $-2 \mathrm{~cm}$ (equivalent to $-0.2 \mathrm{kPa}$ ) was chosen in this study as the recommended head for preventing the macropore water flow (Decagon Devices Inc., 2012). At all test sites, irrigation was ceased at least 6 days at the designated measurement spots prior to conducting the infiltration tests in order to obtain similar soil water contents. No rainfall occurred during the entire test period. Only undisturbed spots were chosen for conducting the tests. All measurements within one test site were taken on the same day except for the test site GI, where the measurements for the respective treatments were taken on subsequent days. The MDI measurements were taken seven times for every site and treatment with the intention of maximum coverage within the available range of the particular treatment plots. The respective measuring spots were usually each several meters apart. In case of uneven surface, a thin layer of nonhydrophobic medium-grained sand was applied to ensure contact between the MDI and the soil surface as recommended in the manual (Decagon Devices Inc., 2012). During the measurement, the volume of the water in the reservoir chamber was documented in regular intervals. Infiltration is computed from the cumulative infiltration records vs. time following Zhang (1997) and Carsel and Parrish (1988) according to Decagon Devices Inc. (2012) fitted by the function

$I=C_{1} t+C_{2} t^{1 / 2}$

where $C_{1}\left(\mathrm{~m} \mathrm{~s}^{-1}\right)$ and $C_{2}\left(\mathrm{~m} \mathrm{~s}^{-1 / 2}\right)$ are parameters related to $\mathrm{HC}$ $\left(C_{1}\right)$ and soil sorptivity $\left(C_{2}\right)$. The $\mathrm{HC}$ of the soil $(k)$ was calculated from

$k=C_{1} / A$

where $C_{1}$ is the slope of the curve of the cumulative infiltration vs. the square root of time, and $A$ is a value relating the corre- sponding van Genuchten parameter according to the pressure head and disc size (Decagon Devices Inc., 2012).

Sporadically occurring negative values for $\mathrm{HC}$ indicate unsteadiness of the particular measurement and were ignored in the further calculation.

\section{Measurement of soil aggregate stability}

Kemper and Rosenau (1986) showed that the results of methods obtaining the water stability of aggregates by using single sieves are highly correlated with results from multiplesieve methods for measuring the aggregate-size distribution and with field phenomena. However, the single sieve methods are generally preferred by most researchers because of their simplicity. Consequently, an improved single sieved wet sieving method initially introduced by Kemper and Koch (1966) became the standard and one of the most common methods for determining the stability of macro-aggregates $(>0.25 \mathrm{~mm}$ ) (Amezketa, 1999; Letey, 1991; Rohoskova and Valla, 2004). According to Marshall et al. (1996), the single sieve method is sufficient for most purposes, as more complex methods are scarcely justified because of their arbitrary nature. However, as there are different methods to determine SAS producing different empirical structural stability indices, comparisons can only be done where similar procedures were used (Díaz-Zorita et al., 2002).

Aggregate stability was determined by wet sieving using the method and machine described by Murer et al. (1993), which is based on the procedure introduced by Kemper and Koch (1966) and later improved by Kemper and Rosenau (1986). In three replications for each respective test site and treatment, air dried soil aggregates sized 1 to $2 \mathrm{~mm}$ were moved in deionized water on a sieve with a mesh size of $0.25 \mathrm{~mm}$ in a vertical distance of $1.27 \mathrm{~cm}$ at a frequency of 42 cycles per minute for 5 minutes. Thus, the unstable parts of the aggregates were released and sieved off. The soil remaining on the sieve (sieve residue 1) was oven dried $\left(24 \mathrm{~h}\right.$ at $\left.105^{\circ} \mathrm{C}\right)$ and weighed. Subsequently, this sieve residue was treated with a dispersing agent $(0.1 \mathrm{~mol}$ solution of $\mathrm{Na}_{4} \mathrm{P}_{2} \mathrm{O}_{7} \times 10 \mathrm{H}_{2} \mathrm{O}$ ) and sieved again, removing the stable soil aggregates. Only sand particles $>0.25 \mathrm{~mm}$ remained on the sieve. The residues were oven dried and weighed again (sieve residue 2). The proportion of stable aggregates was calculated according to Eq. 3:

$\operatorname{SAS}(\%)=[(A-B) /(C-B)] \times 100$ 
as the ratio of the mass of sieve residue $1(A)$ minus the mass of sieve residue $2(B)$ divided by the initial sample mass $(C)$ minus the mass of sieve residue $2(B)$, multiplied by 100 (Murer et al., 1993). To obtain reliable results, the SAS of each soil was determined in triplicates. Each set of results was tested using Dixon's Q-test for outliers $(\alpha=0.1)$. If the outlier analysis was positive the whole set was rejected and the measurements were repeated. SAS is expressed as \% mass of stable aggregates of total aggregate mass.

\section{Analysis of soil properties}

Composite soil samples were taken from a depth of $0-10 \mathrm{~cm}$ at all test sites and treatments by using a gauge auger, collecting 30 subsamples from each test site and treatment, respectively. The samples were subsequently air-dried and sieved to $\leq 2 \mathrm{~mm}$. Soil texture was analyzed by sieving and sedimentation (ISO 11277, 1998). Carbonates were not destroyed as very high carbonate contents in some soils highly contribute to the soil's texture, thus, dissolving the carbonates prior to texture analysis would have led to unrealistic results. Gravimetric water content (WC) was determined after drying at $105^{\circ} \mathrm{C}$ for $24 \mathrm{~h} . \mathrm{A} \mathrm{C} / \mathrm{N}$ Analyzer (Elementar Vario EL) was used for the quantification of total carbon and nitrogen content and a DIMATOC $2000 \mathrm{C}$ Analyzer (Dimatec, Germany) was used for determining $\mathrm{CaCO}_{3}$ content by detecting the release of $\mathrm{CO}_{2}$ after $\mathrm{H}_{3} \mathrm{PO}_{4}$ addition. Exchangeable sodium percentage (ESP) was measured and calculated from the SAR of the saturated soil-paste extract after Rhoades and Miyamoto (1990) and U.S. Salinity Laboratory Staff (1954). Soil salinity was determined as the electrical conductivity at $25^{\circ} \mathrm{C}$ in the saturated paste extract $\left(\mathrm{EC}_{\mathrm{e}}\right)$. The results are shown in Table 2 .

\section{Statistical analysis}

The median, mean and standard deviation of HC and SAS were calculated for every test site. A Mann-Whitney U test for independent samples was performed for the parameter $\mathrm{HC}$ for every orchard to check for differences between irrigation water types (FW vs. TWW). Significances of difference in SAS were tested using independent samples t-test. All statistical analyses were performed with Microsoft Excel 2010 and SPSS (version 20).

\section{RESULTS \\ Soil properties}

The cessation of irrigation prior to sampling led to homogeneous water contents at all operating test sites (AK, RP, YO). The differences in WC for the TWW and FW-treatments were between $0.2 \%$ and $3.2 \%$, except at GI, where a difference of $25.1 \%$ was measured, presumably as a consequence of the uncontrolled circumstances of the fallow plantation. Some heterogeneity was observed between the test site textures. Clay contents ranged from $44.2 \%$ (GI FW) to $59.2 \%$ (YO FW) and sand contents ranged from $2.1 \%$ (RP TWW) to $13.2 \%$ (GI FW). The test sites $\mathrm{AK}, \mathrm{RP}$ and $\mathrm{YO}$ had $\mathrm{CaCO}_{3}$ contents $<3 \%$, in contrast to GI, where the carbonate content ranged from 38.1 to $39.9 \%$ (Table 2).

The soil organic carbon (SOC) and $\mathrm{N}$ contents of soils from FW and TWW irrigated orchards showed no relation with irrigation water quality. The $\mathrm{pH}$ values on TWW plots were similar or slightly higher than on $\mathrm{FW}$ plots. The $\mathrm{CaCO}_{3}$ contents were comparable or higher at TWW irrigated sites compared to $\mathrm{FW}$ irrigated sites. As a general trend, $\mathrm{EC}_{\mathrm{e}}$ was higher in soils from TWW irrigated plots, with increases by $21.9 \%$ (YO) to $93.9 \%$ (RP) compared to those observed in the respective FW irrigated plots. The ESP of the TWW irrigated plots were 3 to 10 times higher in the TWW irrigated soils at YO, AK and RP. Only at GI, the ESP values were almost similar under both treatments (FW 9.3\%, TWW 8.1\%).

\section{Hydraulic conductivity}

The cumulative infiltration over time is lower at all TWW test sites compared to their adjacent FW sites, as displayed in Fig. 1 for the sites AK, RP and YO. Thus, the TWW irrigated sites showed consistently lower HC values compared to the corresponding FW sites (Fig. 2). This applies for both the mean and the median values of the measurements. With a reduction of $43.0 \%$ (RP), $49.1 \%$ (GI), 49.5\% (YO) and 50.7\% (AK), mean $\mathrm{HC}$ values were roughly halved. A Mann-Whitney $U$ test for independent samples was performed for each orchard comparing $\mathrm{HC}$ between FW and TWW treatments to determine the significance of these differences. Soils from AK and GI showed no significant differences between the treatments, whereas the results for RP and YO revealed significant differences of $\mathrm{HC}$ between the FW and TWW irrigated plots (Table 3).

Table 2. Selected physical and chemical properties of the soils at the four test sites and freshwater (FW) or treated wastewater (TWW) treatments, respectively. Except for WC, values are derived from composite samples.

\begin{tabular}{|c|c|c|c|c|c|c|c|c|}
\hline \multirow{3}{*}{$\begin{array}{l}\text { Test site } \\
\text { Crop } \\
\text { Treatment } \\
\end{array}$} & \multicolumn{2}{|c|}{$\mathrm{AK}$} & \multicolumn{2}{|c|}{ GI } & \multicolumn{2}{|c|}{ RP } & \multicolumn{2}{|c|}{$\mathrm{YO}$} \\
\hline & \multicolumn{2}{|c|}{ Avocado } & \multicolumn{2}{|c|}{ Banana } & \multicolumn{2}{|c|}{ Pear } & \multicolumn{2}{|c|}{ Mango } \\
\hline & FW & TWW & FW & TWW & $\mathrm{FW}$ & TWW & FW & TWW \\
\hline WC (\%) & 14.6 & 14.4 & 50.7 & 25.6 & 20.0 & 23.2 & 28.8 & 31.1 \\
\hline sand (\%) & 11.3 & 12.0 & 13.2 & 13.1 & 2.9 & 2.1 & 6.1 & 5.0 \\
\hline clay (\%) & 50.7 & 47.3 & 44.2 & 45.1 & 53.3 & 55.5 & 59.2 & 56.7 \\
\hline $\mathrm{CaCO}_{3}(\%)$ & 1.8 & 2.4 & 38.1 & 39.9 & 0.9 & 0.9 & 0.4 & 2.9 \\
\hline SOC $(\%)$ & 1.15 & 1.27 & 1.65 & 1.52 & 1.28 & 0.82 & 2.16 & 1.80 \\
\hline $\mathrm{N}(\%)$ & 0.14 & 0.18 & 0.20 & 0.21 & 0.14 & 0.10 & 0.24 & 0.21 \\
\hline $\mathrm{pH}$ & 7.7 & 7.8 & 7.7 & 7.7 & 7.6 & 7.7 & 7.3 & 7.7 \\
\hline $\mathrm{EC}_{\mathrm{e}}(\mathrm{mS} / \mathrm{cm})$ & 1.73 & 3.27 & 1.78 & 2.77 & 0.49 & 0.95 & 0.82 & 1.00 \\
\hline ESP & 2.1 & 16.2 & 9.3 & 8.1 & 1.4 & 15.6 & 2.3 & 9.2 \\
\hline
\end{tabular}

WC initial soil water content, $\mathrm{CaCO}_{3}$ calcium carbonate, $\mathrm{SOC}$ soil organic carbon, $\mathrm{N}$ nitrogen, $\mathrm{EC}_{\mathrm{e}}$ electrical conductivity of the saturated paste extract, $\mathrm{ESP}$ exchangeable sodium percentage 
Table 3. Effects of irrigation water quality on unsaturated hydraulic conductivity (HC, $\mathrm{N}=7)$ and stability of soil aggregates $<2 \mathrm{~mm}(\mathrm{SAS}$, $\mathrm{N}=3$ ) at the four test sites, comparing freshwater $(\mathrm{FW})$ and treated wastewater $(\mathrm{TWW})$ treatments.

\begin{tabular}{|c|c|c|c|c|c|c|c|c|c|c|c|c|}
\hline \multirow[b]{3}{*}{ Test site } & \multicolumn{7}{|c|}{$\mathrm{HC}(\mathrm{mm} / \mathrm{h})$} & \multicolumn{5}{|c|}{ SAS (\%) } \\
\hline & \multicolumn{3}{|c|}{ FW } & \multicolumn{3}{|c|}{ TWW } & \multirow{2}{*}{$\mathrm{p}(\mathrm{U})$} & \multicolumn{2}{|c|}{ FW } & \multicolumn{2}{|c|}{ TWW } & \multirow{2}{*}{$p(t)$} \\
\hline & $\mathrm{MN}$ & ME & SD & $\mathrm{MN}$ & ME & SD & & $\mathrm{MN}$ & SD & $\mathrm{MN}$ & SD & \\
\hline$\overline{\mathrm{AK}}$ & 29.66 & 25.96 & 10.91 & 14.60 & 13.62 & 11.55 & 0.138 & 45.11 & 1.31 & 35.90 & 1.17 & $0.001 * *$ \\
\hline GI & 11.89 & 10.15 & 9.18 & 6.04 & 2.50 & 7.17 & 0.295 & 52.68 & 0.18 & 46.72 & 0.65 & $0.002 * *$ \\
\hline RP & 39.19 & 39.81 & 14.28 & 22.36 & 19.99 & 11.94 & $0.038^{*}$ & 70.73 & 0.02 & 60.91 & 0.47 & $0.001 * *$ \\
\hline YO & 62.69 & 66.91 & 21.06 & 31.65 & 33.20 & 8.87 & $0.015^{*}$ & 49.07 & 0.48 & 33.17 & 0.14 & $0.000^{* * *}$ \\
\hline
\end{tabular}

MN mean, ME median, SD standard deviation, p p-value

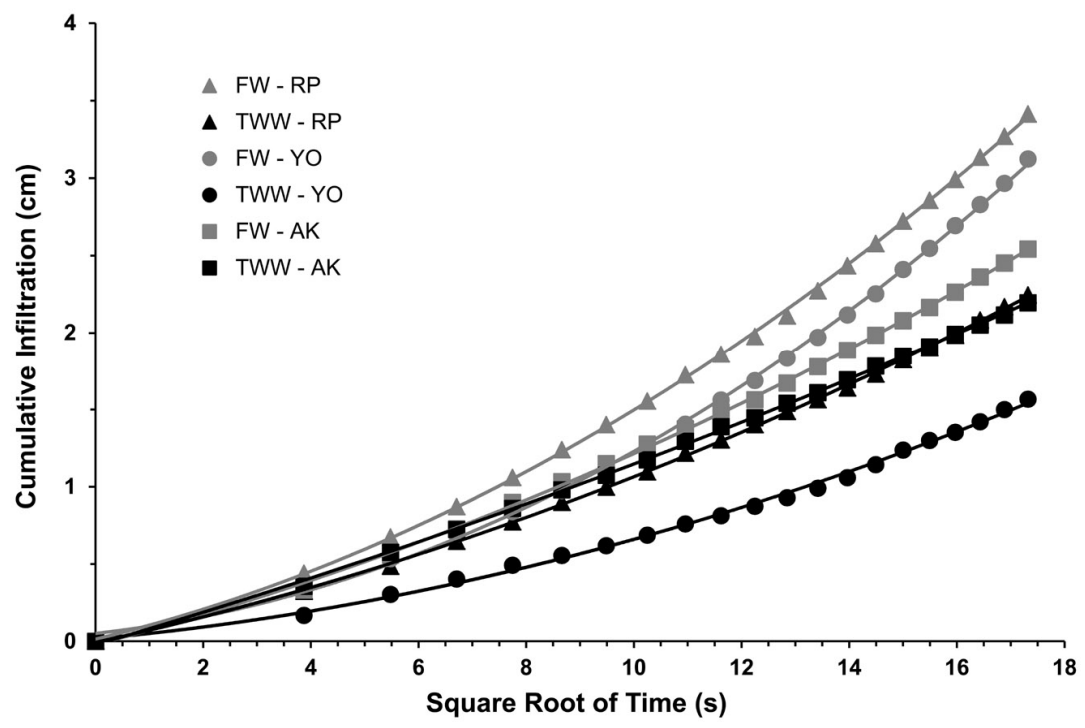

Fig. 1. Mean values of cumulative infiltration $(\mathrm{cm})$ versus square root of time (s) within the first 300 seconds of infiltration for the FW(grey symbols) and TWW-irrigated (black symbols) test sites AK, RP and YO (N = 7).

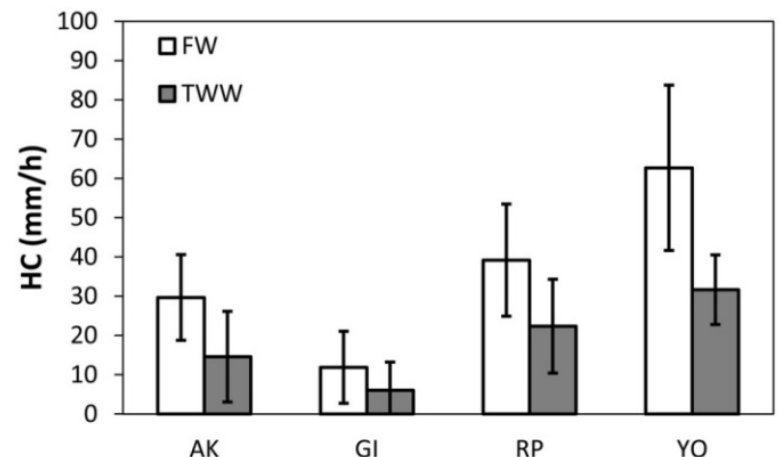

Fig. 2. Irrigation water quality effects on hydraulic conductivity (HC) as determined in the field at the four test sites using the mini disc infiltrometer $(\mathrm{N}=7$, mean and $\mathrm{SD})$.

\section{Soil aggregate stability}

The SAS observations revealed significant differences between the plots irrigated with FW and TWW. The soil samples taken from the TWW irrigated plots showed consistently low-

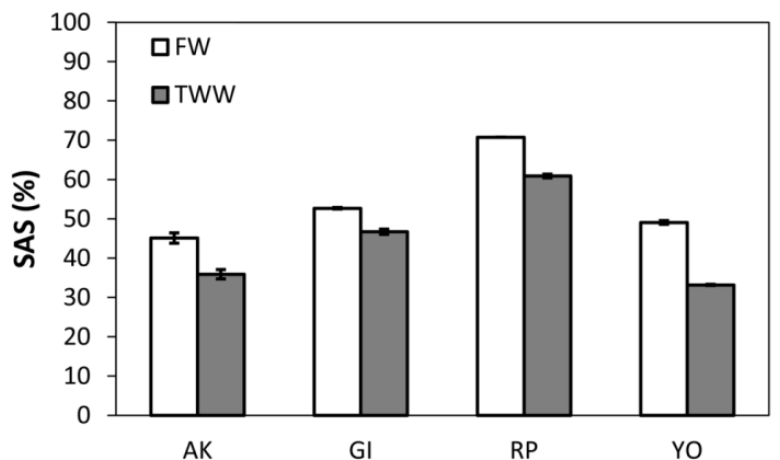

Fig. 3. Irrigation water quality effects on soil aggregate stability (SAS) soil aggregates $<2 \mathrm{~mm}$ obtained from the four test sites $(\mathrm{N}=$ 3 , mean and SD).

er SAS values than those taken from the FW plots (Fig. 3). Mean SAS values of the TWW plots were lower by $11.3 \%$ (GI) to $32.4 \%$ (YO) compared to the corresponding FW plots. In this context, no correlation of magnitude and gradation with clay or organic content was found (Table 3). 


\section{DISCUSSION}

Changes in soil sodicity properties associated with TWW irrigation have been discussed frequently. It is generally reported that irrigation with water of higher SAR leads to elevated SAR in the soil solution, accompanied by elevated soil ESP values (Feigin et al., 1991). This is in accordance with the results of this study, where the particular sites irrigated with water of higher SAR showed higher sodicity values. The same applies to soil salinity, as the particular test sites receiving water of higher salinity showed higher $\mathrm{EC}_{\mathrm{e}}$ values. This is also applicable for the test site GI, although the FW properties display a lower $\mathrm{EC}_{\mathrm{e}}$ value, but higher SAR compared with the TWW properties.

There are numerous studies explaining the effects of TWW irrigation compared to $\mathrm{FW}$ irrigation on $\mathrm{HC}$ and SAS. But for $\mathrm{HC}$, results obtained from in-situ studies are very scarce, as most studies focused on laboratory experiments only, using soil samples collected in the field (Lado and Ben-Hur, 2010; Levy et al., 1999; Levy et al., 2005; Tarchitzky et al., 1999). The benefits of laboratory studies are the opportunity to control environmental parameters and to gain possibly more accurate results. However, these experiments do not necessarily represent real field conditions. Tension disc infiltrometers, with all their limitations, have been shown to be very suitable to determine soil hydraulic properties in the field, especially since obtaining the results is simple and fast, compared to other methods (Angulo-Jaramillo et al., 2000). As macropore flow is prevented due to the applied negative potential when measuring $\mathrm{HC}$ with the MDI, this method reflects normal rainfall or micro irrigation conditions (Minasny and George, 1999).

At all test sites, the TWW irrigated sites showed lower hydraulic conductivities than their adjacent FW irrigated counterparts. The decrease of $\mathrm{HC}$ ranged from -43.0 to $-50.7 \%$, which can be considered consistent in magnitude. As a consequence, the impaired HC of TWW irrigated clayey soils will facilitate surface runoff generation during high intensity precipitation. Rainfall events of $>32 \mathrm{~mm} / \mathrm{d}$ contribute a major proportion to the total precipitation rate in central and northern Israel (Yosef et al., 2009). Thus, TWW sites like GI with $\mathrm{HC}$ rates of $6 \mathrm{~mm} / \mathrm{h}$ and lower might show an increased susceptibility to soil erosion, especially if this low infiltration rate would be further reduced through splash effects. Potential relationships between the reduction rates and other soil properties like texture, sodicity or salinity could not be observed.

The observed decreasing effect of TWW irrigation on cumulative infiltration and $\mathrm{HC}$ of clayey soils is in accordance with prior findings (i. a. Bhardwaj et al., 2007; Gharaibeh et al., 2007). To the knowledge of the authors, this study is the first to compare the unsaturated $\mathrm{HC}$ of clayey soils irrigated with FW and TWW on adjacent test sites in-situ. Assouline and Narkis (2011) applied the MDI in a column study with disturbed clayey soil samples from a TWW- and FW-irrigated test site and showed lower infiltration rates for the TWW-irrigated samples. Vogeler (2009), using disc permeameters, calculated the HC of wastewater and TWW disposal sites and adjacent non-irrigated areas on sandy loam (site Taupo, T) and loamy sand (site Levin, $\mathrm{L})$. At a preset tension of $-10 \mathrm{~mm}$ (equivalent to $-0,1 \mathrm{kPa}$ ), $\mathrm{HC}$ was shown to be higher at the disposal sites compared to the control sites (T: $16.24 \mathrm{~mm} / \mathrm{h}$ vs. $7.79 \mathrm{~mm} / \mathrm{h}$; L: 34.46 vs. $13.3 \mathrm{~mm} / \mathrm{h}$ ). The rates measured are within the same magnitude as the rates in this study, yet they were measured at lower tension on sandier soils than in the present study.

The low HC in the TWW irrigated plots may be further reduced during periods of intense rainfall through soil surface sealing from slaking of soil aggregates, as indicated by the consistently lower SAS of TWW irrigated soils compared to the adjacent FW irrigated soils. This is in accordance with Levy and Mamedov (2002), who measured lower stability ratios of soil samples obtained from TWW irrigated sites compared to FW irrigated sites by using the high-energy-moisture-characteristics method, which is based on differences in water retention curves for fast-wetted and slow-wetted aggregates from replicate soil samples (Nimmo, 2004). In that study, TWW sites showed consistently higher soil ESP values. This is also the case for the present study, except for the test site GI where the soil from the TWW irrigated plot showed a slightly lower ESP value than the soil from the adjacent FW plot. Moreover, it could be presumed that higher total suspended solid (TSS) loads in TWW are associated with the HC reduction, as the TSS freight leads to clogging of soil pores, as stated e.g. by Vinten et al. (1983), Viviani and Iovino (2004), and Sepaskhah and Karizi (2011). Although the TSS loads of the TWW remain typical for TWW which underwent secondary treatment (Feigin et al., 1991), the hazard of soil clogging when using TWW for irrigation is imminent. Viviani and Iovino (2004) inferred that clayey soils are more prone to reduction of $\mathrm{HC}$ caused by TWW irrigation than loamy soils. It is assumed that clay dispersion related to higher soil SAR caused by higher sodium loads of the irrigation water is another main effect reducing HC in TWW irrigated soils. This interpretation is in line with findings by Tarchitzky et al. (1999) and Warrington et al. (2007). The findings of the present study are suggesting a similar effect, as the sodium concentration within the irrigation water were at least similar (GI), but at the other three of the four test sites 3.5 (YO) to 6.5 (RP) times higher in the TWW than in the FW.

To our knowledge, this study is the first to utilize results gained from MDI field tests comparing $\mathrm{HC}$ of FW and TWW irrigated adjacent test sites. Additional findings from accompanying studies within the same measuring campaign focusing on the effects of TWW irrigation on the occurrence of SWR were reported previously (Schacht et al., 2014). It could be shown that the TWW irrigated sites exhibited higher repellency index values than the $\mathrm{FW}$ irrigated sites. In this context, a general limitation of the method of measuring soil hydraulic properties with the MDI has to be considered. To ensure optimal contact between the porous sintered steel disc of the MDI and the often rough soil surface, a thin layer of non-hydrophobic mediumgrained sand was applied usually as recommended in the user's manual (Decagon Devices Inc., 2012). This practice might alter the properties of the soil surface in relation to SWR and infiltration. However, as for the measurement itself the good hydraulically contact between the MDI and the soil surface is essential, this potential alteration is inevitable.

Nevertheless, the overall effects of irrigation water quality on soil hydraulic properties remain complex, as there are many factors to be considered. This was partially shown by Levy et al. (2005), who performed column studies with various soils from Israel, finding significant triple interactions in loamy, sandy clay and clay among water quality, wetting rate and ESP in their effect on HC. They recommended a simultaneous consideration of water quality, wetting rate and sodicity when estimating soil HC. Multiple factors interact within the system of soil hydraulic properties and structure relation, such as irrigation water quality, soil texture and organic carbon content as cementing agents, soil chemical properties, precipitation regime with determining drainage, land use and irrigation method. These interdependent factors become even more complex, when the on-site experimental setting limits the controllability of the experimental circumstances. As laboratory settings might not reflect the actual processes in the field, laboratory experiments and on-site 
experiments like the present study have to complement each other. Thus, this study proves that effects from TWW irrigation on soil hydraulic properties can be determined using simple field methods. The results from the on-site experiments indicate a strong effect of TWW irrigation, reducing soil HC and SAS when compared with FW irrigation. Consequently, irrigated soils and particularly those irrigated with water of poorer quality need to be managed carefully in order to conserve soil integrity and subsequent soil fertility.

\section{CONCLUSION}

The results of this study show that irrigation with TWW reduces field soil hydraulic conductivity and soil aggregate stability. This is attributed to the TWW induced increases in soil sodicity and salinity, parameters that are important indicators for soil quality. Further studies on this are recommended to improve site-specific irrigation water and leaching management, which appears to be crucial in order to prevent a deterioration of soil quality as a consequence of irrigation with TWW.

Acknowledgements. The authors would like to thank Yona Chen, Jorge Tarchitzky, Tsila Aviad, Abraham Gilboa and Nurit ben Hagai for supporting the field trials and scientifical advice. Thanks to Justin Richardson for text editing. The work was part of the GLOWA Jordan River project, which was funded by the German Ministry of Science and Education (BMBF) under the grant 01LW0501A1.GLOWA JR.

\section{REFERENCES}

Amezketa, E. 1999. Soil aggregate stability: A review. J. Sustain. Agr., 14, 83-151.

Angulo-Jaramillo, R., Vandervaere, J.P., Roulier, S., Thony, J.L., Gaudet, J.P., Vauclin, M., 2000. Field measurement of soil surface hydraulic properties by disc and ring infiltrometers: A review and recent developments. Soil Till. Res., 55, 1-29.

Assouline, S., Narkis K., 2011. Effects of long-term irrigation with treated wastewater on the hydraulic properties of a clayey soil. Water Resour. Res., 47, 8, DOI: 10.1029/2011WR010498/

Bhardwaj, A.K., Goldstein, D., Azenkot, A., Levy, G.J., 2007. Irrigation with treated wastewater under two different irrigation methods: Effects on hydraulic conductivity of a clay soil. Geoderma, 140, 199-206.

Bond, W.J., 1998. Effluent irrigation - an environmental challenge for soil science. Aust. J. Soil Res., 36, 543-555.

Brenner, A., 2012. Limitations and challenges of wastewater reuse in Israel. In: Quercia, F.F., Vidojevic, D. (Eds.): Clean Soil and Safe Water. Springer, Dordrecht.

Carsel, R.F., Parrish, R.S., 1988. Developing joint probability distributions of soil water retention characteristics. Water Resour. Res., 24, 755-769.

Dan, J., Yaalon, D.H., Koyumdjisky, H., Raz, Z., 1972. The soil association map of Israel. Israel J. Earth Sci., 21, 29-49.

Decagon Devices Inc., 2012. Mini disk infitrometer user's manual version 10. Decagon Devices In., Pullman.

Díaz-Zorita, M., Grove, J.H., Perfect, E., 2002. Aggregation, fragmentation and structural stability measurement. In: Lal, R. (Ed.): Encyclopedia of Soil Science. Marcel Dekker, New York.

Feigin, A., Ravina, I., Shalhevet, J., 1991. Irrigation with Treated Sewage Effluent: Management for Environmental Protection. Springer, Berlin.
Friedler, E., 2001. Water reuse - an integral part of water resources management: Israel as a case study. Water Policy, 3, 29-39.

Gharaibeh, M., Eltaif, N., Al-Abdullah, B., 2007. Impact of field application of treated wastewater on hydraulic properties of vertisols. Water Air Soil Poll., 184, 347-353.

Halliwell, D.J., Barlow, K.M., Nash, D.M., 2001. A review of the effects of wastewater sodium on soil physical properties and their implications for irrigation systems. Aust. J. Soil Res., 39, 1259-1267.

Hamilton, A.J., Stagnitti, F., Xiong, X., Kreidl, S.L., Benke, K.K., Maher, P., 2007. Wastewater irrigation: The state of play. Vadose Zone J., 6, 823-840.

Inbar, Y., 2007. New standards for treated wastewater reuse in Israel. In: Zaidi, M. (Ed.) Wastewater Reuse-Risk Assessment, Decision-Making and Environmental Security. Springer, Dordrecht.

Israeli Water Authority, 2014. Water Consumption Survey 2012 - Consumption from 1996 to 2012 [Online]. Available: http://www.water.gov.il/Hebrew/ProfessionalInfoAndData/A llocation-Consumption-and-production/20122/targets19962012.pdf (In Hebrew.) [Accessed 2014/06/01]

Kemper, W.D., Koch, E.J., 1966. Aggregate stability of soils from western United States and Canada: measurement procedure, correlations with soil constituents. U.S. Department of Agriculture Technical Bulletin, Vol. 1355.

Kemper, W.D., Rosenau, R.C., 1986. Aggregate stability and size distribution. In: Klute, A. (Ed.): Methods of Soil Analysis. Part 1: Physical and Mineralogical Methods. American Society of Agronomy-Soil Science Society of America, Madison.

Krasilnikov, P., Arnold, R.W., 2009. Soil classification of Israel. In: Krasilnikov, P., Ibánez Martí, J.J., Arnold, R.W., Shoba, S. (Eds.): A Handbook of Soil Terminology, Correlation and Classification. Earthscan, London.

Lado, M., Ben-Hur, M., 2010. Effects of irrigation with different effluents on saturated hydraulic conductivity of arid and semiarid soils. Soil Sci. Soc. Am. J., 74, $23-32$.

Lahav, O., Kochva, M., Tarchitzky, J., 2010. Potential drawbacks associated with agricultural irrigation with treated wastewaters from desalinated water origin and possible remedies. Water Sci. Technol., 61, 2451-2460.

Le Bissonnais, Y., Arrouays, D., 1996. Aggregate stability and assessment of soil crustability and erodibility: I. Theory and methodology. Eur. J. Soil Sci., 47, 425-437.

Letey, J., 1991. The study of soil structure - science or art. Aust. J. Soil Res., 29, 699-707.

Levy, G.J., 2011. Impact of long-term irrigation with treated wastewater on soil-structure stability - The Israeli experience. Israel J. Plant Sci., 59, 95-104.

Levy, G.J., Mamedov, A.I., 2002. High-energy-moisturecharacteristic aggregate stability as a predictor for seal formation. Soil Sci. Soc. Am. J., 66, 1603-1609.

Levy, G.J., Rosenthal, A., Tarchitzky, J., Shainberg, I., Chen, Y., 1999. Soil hydraulic conductivity changes caused by irrigation with reclaimed waste water. J. Environ. Qual., 28, $1658-1664$.

Levy, G.J., Mamedov, A.I., Goldstein, D., 2003. Sodicity and water quality effects on slaking of aggregates from semi-arid soils. Soil Sci., 168, 552-562.

Levy, G.J., Goldstein, D., Mamedov, A.I., 2005. Saturated hydraulic conductivity of semiarid soils: Combined effects of salinity, sodicity, and rate of wetting. Soil Sci. Soc. Am. J., 69, 653-662. 
Magesan, G.N., Williamson, J.C., Sparling, G.P., Schipper, L.A., Lloyd-Jones, A.R., 1999. Hydraulic conductivity in soils irrigated with wastewaters of differing strengths: Field and laboratory studies. Aust. J. Soil Res., 37, 391-402.

Magesan, G.N., Williamson, J.C., Yeates, G.W., Lloyd-Jones, A.R., 2000. Wastewater $\mathrm{C}: \mathrm{N}$ ratio effects on soil hydraulic conductivity and potential mechanisms for recovery. Bioresource Technol., 71, 21-27.

Maher, P., Hermon, K., Ierodiaconou, D., Stagnitti, F., Allinson, G., Armstrong, R., Leblanc, M., De Rooij, G.H., Hogervorst, F., Bloem, E., 2004. Recycled effluent irrigation in vineyards: An Australian case study. II. Management for sustainability. Recent Res. Dev. Crop Sci., 1, 433-449.

Marshall, T.J., Holmes, J.W., Rose, C.W., 1996. Soil Physics. Cambridge University Press, Cambridge.

Milano, M., Ruelland, D., Fernandez, S., Dezetter, A., Fabre, J., Servat, E., 2012. Facing climatic and anthropogenic changes in the Mediterranean basin: What will be the medium-term impact on water stress? C. R. Geosci., 344, 432-440.

Minasny, B., George, B.H., 1999. The measurement of soil hydraulic properties in the field. In: Cattle, S.R., George, B.H. (Eds.): Proc. DAMOS'99 workshop Describing, analysing and managing our soil. The University of Sydney and the Australian Soil Science Society Inc. (NSW Branch), Sydney.

Murer, E.J., Baumgarten, A., Eder, G., Gerzabek, M.H., Kandeler, E., Rampazzo, N., 1993. An improved sieving machine for estimation of soil aggregate stability (SAS). Geoderma, 56, 539-547.

Nimmo, J.R., 2004. Aggregation: Physical aspects. In: Hillel, D. (Ed.): Encyclopedia of Soils in the Environment. Academic Press, London.

Provizor, M., 2009. Water reuse as a national policy. In: Proc. Water Environment Federation Technical Exhibition and Conference, Orlando, Florida, 10-14 October 2009, pp. 6524-6531.

Rhoades, J.D., Miyamoto, S. 1990. Testing soils for salinity and sodicity. In: Westermann, R.L. (Ed.): Soil Testing and Plant Analysis. Soil Science Society of America, Madison.

Rohoskova, M., Valla, M., 2004. Comparison of two methods for aggregate stability measurement - A review. Plant Soil Environ., 50, 379-382.

Schacht, K., Chen, Y., Tarchitzky, J., Lichner, L., Marschner, B., 2014. Impact of treated wastewater irrigation on water repellency of Mediterranean soils. Irrig. Sci., 32, 369-378.
Sepaskhah, A.R., Karizi, A., 2011. Effects of alternate use of wastewater and fresh water on soil saturated hydraulic conductivity. Arch. Agron. Soil Sci., 57, 2, 149-158.

Shainberg, I., Letey, J. 1984. Response of soils to sodic and saline conditions. Hilgardia, 52, 1-57.

Shannon, M.A., Bohn, P.W., Elimelech, M., Georgiadis, J.G., Marinas, B.J., Mayes, A.M., 2008. Science and technology for water purification in the coming decades. Nature, 452, 301-310.

Smiatek, G., Kunstmann, H., Heckl, A., 2011. High-resolution climate change simulations for the Jordan River area. J. Geophys. Res.-Atmos., 116, D16.

Tarchitzky, J., Golobati, Y., Chen, Y., Keren, R., 1999. Wastewater effects on montmorillonite suspensions and hydraulic properties of sandy soils. Soil Sci. Soc. Am. J., 63, 554-560.

Tarchitzky, J., Lerner, O., Shani, U., Arye, G., LowengartAycicegi, A., Brener, A., Chen, Y., 2007. Water distribution pattern in treated wastewater irrigated soils: hydrophobicity effect. Eur. J. Soil Sci., 58, 573-588.

U.S. Salinity Laboratory Staff, 1954. Diagnosis and Improvement of Saline and Alkali Soils. USDA Handbook 60. U.S. Government Print Office, Washington.

Vinten, A.J.A., Mingelgrin, U., Yaron, B., 1983. The effect of suspended solids in wastewater on soil hydraulic conductivity: II. Vertical distribution of suspended solids. Soil Sci. Soc. Am. J., 47, 408-412.

Viviani, G., Iovino, M., 2004. Wastewater reuse effects on soil hydraulic conductivity. J. Irrig. Drain. E.-ASCE, 130, 476484.

Vogeler, I., 2009. Effect of long-term wastewater application on physical soil properties. Water Air Soil Poll., 196, 1, 385392.

Warrington, D.N., Goldstein, D., Levy, G.J., 2007. Clay translocation within the soil profile as affected by intensive irrigation with treated wastewater. Soil Sci., 172, 692-700.

Yosef, Y., Saaroni, H., Alpert, P., 2009. Trends in daily rainfall intensity over Israel 1950/1-2003/4. Open Atmos. Sci. J., 3, 196-203.

Zhang, R., 1997. Determination of soil sorptivity and hydraulic conductivity from the disk infiltrometer. Soil Sci. Soc. Am. J., 61, 1024-1030.

Received 28 July 2014 Accepted 18 November 2014 